\title{
Driving Under the Influence of Our Fathers*
}

\author{
September 7, 2009 \\ Randi Hjalmarsson \\ University of Maryland \\ Matthew J. Lindquist \\ Stockholm University
}

\begin{abstract}
This paper studies intergenerational correlations in drunk driving between fathers and their children using the Stockholm Birth Cohort. We find strong evidence of an intergenerational drunk driving relationship. Cohort members who have fathers with a drunk driving record have 2.59 times higher odds of having a drunk driving conviction themselves than cohort members with non-drunk driving fathers. We then go on to investigate the underlying mechanisms that give rise to these correlations. The results provide compelling evidence that at least some of this relationship represents a behavior-specific transference from fathers to their children. Specifically, much of the raw father-child drunk driving relationship persists over and above controls for a number of potential explanations, including that the relationship is: (i) a by-product of parental alcoholism, (ii) symptomatic of a general pattern of non-law abiding behavior, (iii) attributable to inherited ability and physical characteristics, and (iv) accounted for by common background variables or social factors. We then go on to show how this mechanism may change over time. As cohort members age into adulthood, the father-child drunk driving relationship appears to be driven by a more general behavioral transference mechanism and can be accounted for by parental alcoholism and non-law abiding behavior.
\end{abstract}

Keywords: alcohol, crime, drunk driving, illegal behavior, intergenerational crime, intergenerational mobility, risky behavior.

JEL codes: J62, K42.

\footnotetext{
* We would like to thank Philip Cook, Sten-Åke Stenberg and seminar participants at the European Economic Association's 2009 conference and Stockholm University for their valuable comments ands suggestions. We would also like to thank Sandu Cojocaru for his excellent research assistance. Partial funding for this project has been provided by the U.S. National Science Foundation, SES-0819032. Contact address for Randi Hjalmarsson: 4131 Van Munching Hall, University of Maryland, School of Public Policy, College Park, Maryland 20742, Office Phone: 301-405-4390, Cell: 203-435-2954, Fax: 301-403-4675, and Email: rhjalmar@umd.edu. Contact address for Matthew J. Lindquist: Department of Economics, Stockholm University, SE-106 91 Stockholm, Sweden, Phone: 46+8+163831, Fax: 46+8+159482, and Email: Matthew.Lindquist@ne.su.se.
} 


\section{Introduction}

In 2005, nearly 1.4 million drivers were arrested in the United States for driving under the influence of alcohol or narcotics (Department of Justice 2006). ${ }^{1}$ That same year, 16,885 people died in alcohol-related motor vehicle crashes, which is 39 percent of all traffic related deaths in the U.S. (NHTSA 2007). The total cost, above and beyond this human suffering, has been estimated at $\$ 51$ billion per year (Blincoe et al. 2002). Drunk driving is not a problem isolated to the U.S. - a World Health Organization study estimates that more than 30 percent of road traffic fatalities in the European Union are due to alcohol (Anderson and Baumberg, 2006).

Consequently, governments have implemented a number of laws to curb the incidence of drinking and driving, including: zero tolerance laws, beer taxes, regulating the drinking age, lowering blood alcohol content (BAC) levels, and sanctions (ranging from losing one's license to incarceration). Evaluations of these policies generally yield a strong, evidence-based consensus in favor of the view that restricting access to alcohol, raising prices and increasing penalties does, in fact, lower alcohol consumption and decrease episodes of drunken driving, particularly among youths (Cook 2007). ${ }^{2}$

In this paper, we aim to provide new insight into the source of this costly, dangerous behavior using an alternative approach. In particular, we examine this important social and economic problem from an intergenerational perspective. More specifically, we document the extent to which drunk driving is correlated across generations (fathers and their children). We then explore a number of potential explanations of this intergenerational drunk driving

\footnotetext{
${ }^{1}$ This number represents less than one percent of the self-reported episodes of alcohol-impaired driving among U.S. adults each year (Quinlan et al. 2005).

${ }^{2}$ For instance, studies evaluating 0.08 BAC laws include Dee (2001), Eisenberg (2003), Freeman (2007), Cox (2006), and Carpenter and Harris (2005); however, not all of these studies conclude that 0.08 BAC laws are effective. A number of studies find beer taxes to be an effective policy instrument in reducing youth drinking participation (Carpenter et al. 2007) or crash deaths (Ruhm 1996). Carpenter and Dobkin (2009) provide recent strong support for the hypothesis that higher minimum legal drinking ages lower alcohol related traffic fatalities.
} 
correlation: (i) genetics - inherited traits, (ii) external social factors (e.g., low income and education), and (iii) within family behavioral factors. Behavioral mechanisms may include the interaction between parental instability (e.g., substance abuse, mental health problems, divorce, criminality) and child outcomes and various types of role modeling (e.g., gender-specific, gender-neutral, and behavior-specific). ${ }^{3}$ In particular, we aim to identify whether the intergenerational transmission of drunk driving is behavior specific as opposed to being attributed simply to having an alcoholic father or one who has a general disregard for the law.

A better understanding of the family's contribution to this behavior could potentially aide practitioners in designing improved treatments. Our work may also have important implications for cost-benefit analyses of public policies aimed at treating and/or deterring drunk driving. If policies (such as alcohol taxes and treatment programs) reduce drunk driving, and if there is an intergenerational link that is behavioral-specific, then any cost-benefit analysis will necessarily underestimate the true, long-run benefits of such policies if this "second generation effect" is not taken into account. ${ }^{4}$

Although there is a large literature studying different aspects of drunk driving and a large literature evaluating preventative policy measures, we have not managed to find any previous research dealing explicitly with correlations in drunk driving between parents and their children. We suspect that this omission in the literature is largely due to the unusual difficulty posed by the need to obtain individual level data on drunk driving for at least two generations within the same family. There is, however, a small literature using individual level data that studies drunk driving jointly with other forms of criminal behavior. Norström (1996), for example, finds that

\footnotetext{
${ }^{3}$ Our ability to look at gender-specific mechanisms is limited by the low prevalence of drunk driving among females in our data set.

${ }^{4}$ The existence and strength of gene-environment (family behavior) interaction effects will also increase the size of our "second generation effect".
} 
repeat offending drunk drivers tend to fall into one of two categories: (i) those who drive drunk due to problems with alcohol abuse and (ii) those who drive drunk because of their general disdain for abiding by the law. Thus, in this context, repeated drunk driving offenses may be said to be due either to alcoholism or to anti-social behavior. ${ }^{5}$ But are these two types of behavior likely to be passed on within families from one generation to the next? And if so, how?

Extensive research has been done on intergenerational patterns of alcohol use and abuse. ${ }^{6}$ These patterns are, indeed, correlated across generations. Estimates of the increased risk of becoming an alcoholic faced by children of alcoholics range from 4:1 to 9:1 (Windle 1997). These patterns are believed to be transmitted through both social and behavioral mechanisms (Ellis et al. 1997, Jacob and Johnson 1997, Windle 1997) and through genetics (McGue 1997). It is not yet clear, however, which of these mechanisms is most powerful and it is quite likely that there are strong interaction effects between environment and genetics.

Other researchers have examined the intergenerational transference of anti-social behavior including: conduct disorders, antisocial personality disorder, attentiondeficit/hyperactivity disorder, oppositional defiant disorder, aggression, violence, child abuse,

\footnotetext{
${ }^{5}$ In another Swedish study, Hauge (1978) noted that 33 percent of drunk-driving convicts had general alcohol problems and that 63 percent had criminal convictions. Data from a Massachusetts sample of 1,300 DUI defendants suggest that 32.4 percent of all male DUI defendants had been previously arraigned for non-drunk driving offences only, 8.8 percent for previous drunk driving only, and 20.1 percent for both drunk driving and other criminal offences; only 38.7 percent had no previous arraignments (Jacobs 1989). Other determinants of drunk driving studied in the literature include socio-economic status (Hyman 1968), psychological problems (Yoder and Moore 1973, Jacobs 1989), personality traits (Cavaiola and Wuth 2002), demographic characteristics and marital status (Cosper and Mozersky 1968). But it appears that none of these characteristics have been universally accepted by the profession as known determinants of drunk driving behavior. Moskowitz, Walker and Gomberg (1979), for example, find that alcoholics entering residential treatment display a combination of problems, including economic, emotional, employment, family and marital, while DWI offenders do not generally report these problems. Norström (1978) reports no direct effect of demographic characteristics or marital status.

${ }^{6}$ A note for other economists: As pointed out by Kenneth Sher (in De Ribeaux, 1997), one of the first public discussions concerning the quantitative importance of this intergenerational link was the debate between John Maynard Keynes and the psychologist/statistician Karl Pearson concerning the extent to which children of alcoholics suffered from intellectual deficits.
} 
juvenile delinquency and crime. This literature finds strong family resemblances in anti-social and criminal behavior. ${ }^{7}$

Duncan et al. (2005) report parent-child correlations in a wide array of behaviors, attitudes and outcomes (both good and bad), though none of the outcomes considered are alcohol related. They find striking evidence in support of the hypothesis that "likes beget likes" across generations and that "many more specific than general competencies appear to be passed from one generation to the next" (p. 71). They also compare the explanatory power of these behavioral transference mechanisms against several alternative explanations, including shared socioeconomic status and the influence of genetics. Many of the tests are necessarily indirect, but nonetheless provide compelling evidence of the importance of behavioral transference mechanisms.

The current paper investigates the intergenerational correlation in drunk driving and the potential underlying mechanisms using data from The Stockholm Birth Cohort Study. This data set consists of 15,117 individuals born in 1953 who were living in the greater Stockholm metropolitan area in 1963. Most importantly, the data contain drunk driving records of both the birth cohort and their fathers. ${ }^{8}$ The data set also includes information concerning parents' use and

\footnotetext{
${ }^{7}$ See Blazei et al. (2006) for an excellent review of the applied psychology literature. In Hjalmarsson and Lindquist (2007), we studied intergenerational criminal correlations and their underlying mechanisms using data from the Stockholm Birth Cohort Study. Other examples of studies on intergenerational crime include Farrington et al. (2009) and van de Rakt et al. (2009), both published in a special issue of the Journal of Criminal Behavior and Mental Health concerning the intergenerational transmission of anti-social behavior. The economics and sociology literature, on the other hand, tends to focus on the intergenerational transmission of more positive social traits, such as income, education, occupation, status and wealth (Björklund and Jäntti - forthcoming, Erikson and Goldthorpe 1992, Solon 1999). There is, however, a growing literature focusing on the transmission of less desirable outcomes, such as poverty, welfare dependency and poor health (see, e.g., Corak 2006 and Stenberg 2000). Mazumder (2008) studies brother correlations in various outcomes.

${ }^{8}$ Sweden was the second country in the world (after Norway) to criminalize drunk driving (BRÅ 1995). And even though Sweden has, by international standards, a relatively low frequency of reported and convicted drunk drivers (320 per 100,000 persons; BRA 2007), it is still considered to be a major social problem. Between 25 and 40 percent of all traffic deaths each year are alcohol related (Vägverket 2003, 2008). This figure is comparable to the U.S. figure of 39 percent. In a systematic trial study undertaken in 3 of Sweden's 21 counties, police found that 0.24
} 
abuse of alcohol. This information has been excerpted manually from individual dossiers kept by the social welfare authorities and child welfare committees. Not unexpectedly, this information plays a central role in disentangling whether the transference of drunk driving from one generation to the next is behavior specific. This type of information is quite unique and cannot be found in your typical Nordic register data.

We find strong evidence of an intergenerational drunk driving relationship. In particular, cohort members who have fathers with a drunk driving record have 2.59 times higher odds of having a drunk driving conviction themselves than cohort members with non-drunk driving fathers. The odds ratio when restricting the analysis to the sample of sons is 2.57 and it is even larger (7.41) for the sample of daughters.

Much of our empirical analysis relies on regressions of a cohort member's drunk driving behavior on their father's drunk driving behavior; we include various controls in a step-wise fashion to proxy for the potential underlying mechanisms. The results provide compelling evidence that at least some of the intergenerational drunk driving relationship described above represents a behavior-specific transference from fathers to their sons and daughters. Specifically, much of the raw father-child drunk driving relationship persists over and above controls for a number of potential explanations, including that the relationship is: (i) a by-product of parental alcoholism, (ii) symptomatic of a general pattern of non-law abiding behavior, (iii) attributable to inherited ability and physical characteristics, and (iv) accounted for by common background variables or social factors. The latter two explanations appear to be particularly unimportant.

Further analysis indicates, however, that the source of the intergenerational drunk driving relationship may change over time, as cohort members age into adulthood. In particular, the

percent of all tested drivers had blood alcohol levels above the Swedish legal limit (VTI 2007). Previous studies had measured hit rates of about 0.20 percent (Vägverket 2008). 
relationship between the drunk driving behavior of adult sons and their fathers appears to be primarily driven by general alcohol abusing and law breaking behaviors while the relationship observed for juvenile sons appears to be, at least in large part, driven by a behavior-specific transference mechanism. This is consistent with juveniles being more impressionable and likely to treat their fathers as role models and is further evidence of specificity in the intergenerational transmission of bad habits as posited by Duncan et al. (2005). ${ }^{9}$

The rest of this paper is organized as follows. Section 2 describes the Stockholm Birth Cohort. Section 3 documents a set of intergenerational correlations in drunk driving and other alcohol related behaviors. Once this relationship is established, we investigate whether or not this relationship is behavior-specific or generated by a more general mechanism of transference, such as a general disrespect for the law and social norms, in Sections 4 and 5. We conclude with a summary of our main findings and a brief discussion of their policy relevance, as well as ideas for future research.

\section{Data}

Our data come from the Stockholm Birth Cohort (SBC), which was created in 2004/2005 by means of a probability matching of two previously existing longitudinal datasets. ${ }^{10}$ The first is the Stockholm Metropolitan Study 1953-1985, which consists of all children born in 1953 who were living in the Stockholm metropolitan area on November 1, 1963. This study contains a rich

\footnotetext{
${ }^{9}$ Note that Duncan et al. (2005) only look at the relationships between mother's and children's behaviors when young; most child outcomes are measured at age 14. Thus, one cannot compare our findings regarding the mechanisms underlying adult drunk driving behaviors.

${ }^{10}$ Carl-Gunnar Janson and Sten-Åke Stenberg managed and provided the original cohort data, Denny Vågerö organised the follow-up data and Reidar Österman managed the probability matching of the two data sets. Preparing data from the Stockholm Birth Cohort Study is an ongoing collaborative effort by the Swedish Institute for Social Research and by Centre for Health Equity Studies, partly financed by the Swedish Research Council. For a complete description of the project and data set see Stenberg and Vågerö (2006) and Stenberg et al. (2007). Codebooks describing all of the data in more detail are available upon request and will soon be made available online.
} 
set of variables concerning individual, family, social and neighborhood characteristics. The second is The Swedish Work and Mortality Database, which consists of administrative register information on income, work, unemployment, in-patient and mortality data for all individuals living in Sweden in 1980 or 1990 who were born before 1985. The work in this paper is based on data originating from the Stockholm Metropolitan Study, which consists of 15,117 individuals: 7,719 men and 7,398 women. The most important feature of this data is that it contains drunk driving records of both the birth cohort and their fathers. ${ }^{11}$

The drunk driving and other alcohol related variables come from two sources: the official police registrar (person- och belastningsregister, $P B R$ ) and the social registers held by each municipality in the greater Stockholm metropolitan area. Each municipality in Sweden maintains its own social register, which is comprised of dossiers for individuals that have for some reason or another received help from the local social services. These dossiers also include information concerning Child Welfare Committee cases and they include information on drunk driving of both parents and their children. Records concerning parents' drunk driving were most likely kept in the social register for two reasons. First, the Child Welfare Committees collected information on negative parental behavior in order to monitor the welfare of the children in the home. Second, convictions for drunk driving at this time rarely lead to jail sentences, but normally entailed probation, fines and some form of mandatory treatment program. This treatment was provided by the local social services, which kept track of treatment provided to parents.

For the cohort members (both sons and daughters), the PBR contains records of offenses that lead to an official report to the Child Welfare Committees or to a court conviction. For each

\footnotetext{
${ }^{11}$ In the original Stockholm Metropolitan Study, fathers were identified using 3 sources: (1) the 1964 national register of population and income, (2) information from the parish register's office from 1953, and (3) interviews with the cohort members' mothers. The primary goal was to collect information on "rearing" or "social" fathers, hence, fathers may be biological-, adoptive-, or step-fathers.
} 
year from 1966 to the first half of 1984 (i.e., when the cohort members are age 13 through 31), our data include information on the number of drunk driving offenses as well as the sentence that was received for each cohort member. ${ }^{12}$ The social registers also contain drunk driving records for when the cohort members were juveniles (age $13-19) .{ }^{13}$ However, social registers outside of the Stockholm metropolitan area were not searched. This means that cohort members cannot appear in the register until they have moved into the area and that they disappear from this register once they leave the municipality. Of the 15,117 cohort members, 1,373 boys and 1,353 girls (i.e., 18 percent of the birth cohort) were not born in the area, but rather moved into the area some time before November 1, 1963. Also, by November 1, 1970, 503 boys and 444 girls (i.e., 6 percent of the birth cohort) had left the area. For these individuals, data from the social register are (potentially) censured. Data from the police register are not censured in this manner, since it is a nationwide register.

For the fathers, the PBR indicates the number of traffic offense sentences. But, unfortunately, his drunk driving offenses have been summed together with his reckless and/or dangerous driving offenses. So, we do not actually know exactly how many of his traffic convictions pertain to drunk driving and how many pertain to other types of serious traffic

\footnotetext{
${ }^{12}$ In 1941, two categories of drunken driving were established, drunken driving and aggravated drunken driving. The blood alcohol levels for these two crimes were set at $0.08 \%$ and $0.15 \%$, respectively. In 1957 , the blood alcohol level for the lesser of these two offenses was lowered to $0.05 \%$ and in 1990 to $0.02 \%$. In 1994, the blood alcohol content for aggravated drunken driving was lowered to $0.1 \%$.

${ }^{13}$ There is considerable overlap between reports of drunk driving by cohort members under age 20 in the social register and in the police register, mainly due to the fact that the police were obliged to report such incidents to the local Child Welfare Committees. The social register is our preferred source for data on drunk driving among juveniles since it includes reports from other sources than the police, i.e., from the child's school, family members, social workers, neighbors, local shopkeepers, etc. and since the police did not always make official reports for lesser offenses among juveniles.
} 
offenses. ${ }^{14}$ Fortunately, as stated above, the social registers provide a second source of data concerning fathers' (and mothers') drunk driving behavior.

We also make extensive use of data concerning other types of drunken behavior and alcoholism. In particular, we know whether or not the mother and/or father had been fined for public drunkenness. We also know if the father and/or mother had been classified by the social authorities as an alcoholic and whether or not they were subject to institutional treatment or some other action. These data come from the social registers, which only covers the years $1953-1972$ (i.e., when the cohort members were between the ages of zero and 19). For children, we have information on drunken conduct that comes from both the social register (when they are under age 20) and the PBR. The police register covers court convictions and/or fines for drunk and disorderly behavior and other alcohol related offenses up until they reach age 31 .

The SBC study also includes an extensive set of control variables, which we use to help disentangle the source of the intergenerational drunk driving relationship. These variables will be described in more detail when presenting the results.

\subsection{Descriptive Statistics}

Table 1 displays descriptive statistics for male and female cohort members and their parents. Drunk driving is much more prevalent among males than females. This is seen both when comparing the males and females of the birth cohort as well as fathers and mothers. 8.1 percent of the sons have at least one conviction for drunk driving or driving under the influence in either the social register or official police register at any age; for these 613 sons, the average number of

\footnotetext{
${ }^{14}$ We will, however, still make use of this information as a sensitivity check. This is motivated, in part, by the finding of Levitt and Porter (2001) that people with bad driving records are more likely to drive drunk and more likely to get into fatal accidents than other drunk drivers. Thus, this variable may still include valuable information about fathers who are more likely than others to drive after drinking despite the fact that it is not a clean measure of drunken driving.
} 
offenses is 1.59 . In contrast, just 33 daughters ( 0.5 percent) have been convicted an average of 1.61 times. The median number of convictions in both of these groups is one. These gender differences persist when separating out drunk driving as an adult (age 20 or older) versus a juvenile (age 19 or younger). 6.1 and 3.0 percent of sons have a record of drunk driving as an adult and juvenile, respectively, while just 0.4 and 0.1 percent of daughters have such a record. The large percentage among young sons is particularly striking given that drivers in Sweden do not receive their license until age 18 at the earliest.

The gender differences observed among the cohort members are consistent with differences seen for the parents. Mothers have almost no incidences of drunk driving. 1.7 percent of our fathers (1.6 percent in the sample of sons and 1.8 percent in the sample of daughters) have a record of drunken driving between 1953 and 1972 recorded in the social register (Dad drunk driving). If we combine the information that we have from both the social register and the police register, then we find that 4.2 percent of SBC fathers have a conviction for drunk and/or dangerous driving (Dad drunk driving 2). The former measure of paternal drunk driving, which only includes drunk driving, will be used throughout the analysis and robustness checks will be conducted with the latter.

Because of the gender differences observed in Table 1, the majority of our analysis is conducted separately for sons and daughters. In addition, the analysis focuses on the drunk driving behavior of the fathers rather than that of both parents.

Table 1 also provides some information regarding more general alcohol related behaviors; 7.4 percent of sons and 1.9 percent of daughters in our sample have records of drunkenness. Just under two percent of the parents in our sample have been fined for public 
drunkenness. Finally, 4.3 (3.9) percent of fathers and 0.8 (0.5) percent of mothers have been classified as alcoholics for the sample of sons (daughters).

\section{Intergenerational Correlations in Drunk Driving and in Drunken Behavior}

Is there an intergenerational correlation in drunk driving? That is, are children more likely to have been convicted of drunk driving if their fathers have also been convicted of drunk driving? The first row of Table 2 presents the odds ratios that result from univariate logistic regressions of whether the cohort member has any drunk driving record on whether the father has a drunk driving record. There is clearly a strong relationship between fathers' drunk driving and their children's drunk driving at the extensive margin. Children with drunk driving fathers have 2.59 times higher odds of having a drunk driving record themselves than children whose fathers do not have a drunk driving record. The odds ratio when restricting the analysis to the sample of sons is 2.57 and it is even larger (7.41) for the sample of daughters.

The second and third rows of Table 2 examine whether these relationships show up already in our data on juvenile drunk driving. In fact, the odds ratios are even stronger when looking at the juvenile data. The odds ratio is 3.37 for juvenile boys and 11.26 for juvenile daughters. These compare to odds ratios of 2.22 and 6.58 , respectively, for adult sons and daughters. Thus, it would appear that this relationship is fully entrenched by age 19 .

Finally, the last row of Table 2 presents the incidence-rate ratios resulting from a negative binomial regression of the number of cohort member drunk driving offenses (excluding zeros) on whether the father has any drunk driving record. ${ }^{15}$ We do not find any significant "intensive" margin relationship, except (perhaps) for women. ${ }^{16}$ But we do not pursue this

\footnotetext{
${ }^{15}$ Please note that we have no measure of the intensive margin of fathers' drunk driving available to us.

16 The results are the same if we include zeros and, instead, run a zero-inflated negative binomial regression.
} 
marginally significant finding (borderline 10\%), since there are only six women in the data set with more than one conviction for drunk driving. ${ }^{17}$

\section{General vs. Behavioral-Specific Transference}

Is this transfer of behavior from fathers to their children specific to drunk driving, or is this association in drunk driving merely one expression of a general pattern of drunken behavior that is transferred from fathers to their children? To begin to address this question, we have run univariate regressions (similar to those in Table 2) using measures of the drunken behavior of the SBC sons and daughters other than drunk driving as the dependent variable. We can then compare these new odds ratios with those presented in Table 2. If they are smaller, then this would be an indication that the father-child drunk driving relationship is a behavioral-specific transference from the father to his child. If they are of the same magnitude or larger, then it is more likely that the father passes on a more general set of drunken behaviors, which includes (among other things) drunk driving.

In Table 3, we see that all father-son associations at both margins are now insignificant and smaller in magnitude. These results indicate that the father-son drunk driving associations reported in Table 2 may represent a behavioral-specific transference from fathers to sons.

However, the evidence regarding whether the father-daughter association is driven by general or behavioral-specific transference is mixed. On the one hand, the father-daughter relationships remain significant and the odds ratio for adult drunkenness (7.04) is remarkably similar to that for adult drunk driving (6.58). Thus, for daughters, there is some evidence that fathers (and probably mothers too) transfer their drinking behavior to their daughters, which

\footnotetext{
${ }^{17}$ Though the magnitudes differ slightly, most of the results presented in Table 2 do not change qualitatively when using the alternative definition of paternal drunk driving (Dad drunk driving 2), which also includes dangerous driving. The one exception is that the intensive margin for daughters becomes insignificant.
} 
results in similar patterns of drunken behavior that occasionally also includes drunk driving. On the other hand, the magnitude of the relationships for juvenile drunkenness is much smaller than the corresponding relationships for drunk driving, pointing towards a behavior-specific transference story. It is important to keep in mind that drunk driving appears to be an offense mainly committed by men and we should also be open to the idea that the dominant transference mechanism may change as cohort members age into adulthood.

\section{Why is Drunk Driving Correlated across Generations? A Regression Analysis}

Why is drunk driving correlated between fathers and their children? In this Section, we use traditional regression techniques to examine several potential mechanisms. We begin by looking at the extensive margin in Table 4 for both sons (columns (1) through (6)) and daughters (columns (7) through (12)). We then go on to consider in Table 5 whether the underlying mechanisms differ or change as sons age into adulthood. We do not attempt this for daughters, since only 7 daughters have a drunk driving record when they are 19 or younger.

\subsection{Extensive Margin Results}

As seen in Table 2, Columns (1) and (7) of Table 4 present the baseline odds ratios between fathers' drunk driving and sons' and daughters' drunk driving, 2.57 and 7.41, respectively. The remaining columns of Table 4 include additional variables that could potentially explain this raw relationship.

The most straight-forward explanation of the intergenerational correlation in drunk driving is that it is simply a by-product of having parents who abuse alcohol. Since alcohol abuse is a documented correlate of drunk driving (Ehrlich and Selzer 1967, Waller 1967, Selzer 
1969, Yoder and Moore 1973, Ross 1976), it is possible that the intergenerational transference of alcohol use and abuse results in a higher number of drunk driving convictions among both parents and their children. It would therefore be the case that our father-child drunk driving associations are merely symptoms of this general pattern of behavior and not a case of behaviorspecific transference. Thus, we test this explanation by controlling for a measure of fathers' alcohol abuse in columns (2) and (8) of Table 4 and mothers' alcohol abuse in columns (3) and (9). These variables indicate whether or not the father and/or mother has received a diagnosis of alcoholism reported by the social authorities.

Sons of both alcoholic fathers and mothers are significantly more likely to engage in drunk driving behavior. The odds ratio associated with father drunk driving decreases from 2.57 to 1.81 when including these controls, or by approximately 48 percent relative to an odds ratio of one. Note that all such calculations will be made relative to an odds ratio of one. Though parental alcoholism is not significantly related to daughters drunk driving, the odds ratio associated with father drunk driving still decreases by almost 27 percent (from 7.41 to 5.68). Thus, the intergenerational drunk driving relationships persist over and above parental alcoholism. That is, the intergenerational link does not appear to be completely driven by a genetic predisposition to be an alcoholic (if such a predisposition exists) or a nurture mechanism that works solely through alcoholism itself. Rather, it appears to be something that is, at least in part, more specific to the drunk driving behavior. This result is consistent with what we saw in Table 3 .

A second potential explanation of the intergenerational drunk driving relationship that we alluded to in the introduction of this paper is that many fathers may drive drunk because they have a general disdain for abiding by the law. The existence of such a relationship between 
drunk driving and general criminality is supported by the literature. ${ }^{18}$ This non-law abiding norm may then be passed down from fathers to their children, so that they also drive drunk due to this lack of respect for the law. To test this hypothesis, we add a measure of fathers' criminality, i.e. whether or not he has a sentence for any offense other than drunk and dangerous driving in the official police register, to the regressions in columns (4) and (10) of Table 4. Sons with criminal fathers have 1.66 times higher odds of being convicted of drunk driving than sons without criminal fathers. But, controlling for paternal criminality only explains an additional 12 percent of the raw father-son drunk driving odds ratio (from 1.81 to 1.61). Controlling for fathers' criminality in the daughter regressions has a similar effect; the odds ratio on father drunk driving decreases from 5.68 to 5.11 or by an additional 9 percent. Thus, while a father's 'bad example' in general may explain some of the intergenerational drunk driving relationship, much of the relationship is left unexplained.

A third explanation could be the importance of inherent ability and physical characteristics that are partly inherited from one's parents. We control for inherent ability using a sixth grade test of intelligence, a second test of intelligence (for males) taken at the start of compulsory military service, and school grades in sixth grade. ${ }^{19} \mathrm{We}$ also have measures of a number of physical characteristics for most of our sons that were collected during military service. In particular, we control for weight $(\mathrm{kg})$, height $(\mathrm{cm})$, and deviations from normal weight (given height and muscle mass). One justification for the inclusion of these physical attributes is

\footnotetext{
${ }^{18}$ For instance, Argeriuo, McCarty and Blacker (1985) find that more that 75 percent of DWI offenders had been arraigned for one or more criminal offences and 50 percent were arraigned for offences other than DWI, while 68 percent of DWI recidivists had prior criminal record. Beerman, Smith, and Hall (1988) find that the number of both minor and major crimes to be the best predictors of DWI recidivism. Hauge (1978) noted that 63 percent of drunkdriving convicts had previous criminal convictions. Data from a Massachusetts sample of 1,300 DUI defendants suggest that 32.4 percent of all male DUI defendants had been previously arraigned for non-drunk driving offences only, 8.8 percent for previous drunk driving only, and 20.1 percent for both drunk driving and other criminal offences; only 38.7 percent had no previous arraignments (Jacobs 1989).

${ }^{19}$ Of course, we recognize the possibility that these measures may not just capture ability, but may also include information, for instance, about socioeconomic status.
} 
the role that they might play in one's ability to metabolize alcohol and perhaps evade conviction for a drunk driving offense. As seen in column (5) of Table 4, these additional controls do not further explain the father-son drunk driving relationship and, in fact, push the odds ratio back up to 1.66. Controlling for ability in column (11) does, however, decrease the father-daughter drunk driving odds ratio from 5.11 to 4.21 (or by an additional 14 percent).

The fourth and final explanation that we would like to explore is that of common background effects that arise from social class and income. In other words, is there some omitted background characteristic that is correlated with drunk driving behavior for both the father and child? Columns (6) and (12) therefore add in controls for father's class in 1953, father's class in 1963, whether or not the father is Swedish, employment of the household head in 1960, father's total income in 1963, and the education of both the father and the mother. ${ }^{20}$ Once again, these additional controls do not further explain the father-son drunk driving relationship, even though many of the social class variables are themselves significantly related to the sons' drunk driving behavior. In addition, the odds ratio for daughters actually increases back up to 5.15, though it is important to note that almost 70 daughters are dropped from the regression.

Overall, the results in Table 4 indicate that the father-child drunk driving relationship persists over and above a number of potential explanations, including that it is: (i) a by-product of parental alcoholism, (ii) symptomatic of a general pattern of non-law abiding behavior, (iii) attributable to inherited ability and physical characteristics, and (iv) accounted for by common background variables. Thus, while the set of controls included in Table 4 is certainly not exhaustive, there appears to be evidence that at least some of the intergenerational drunk driving

\footnotetext{
${ }^{20}$ Father's income is only available for a single year. By itself, this is likely to be an imperfect measure of permanent income. Therefore, we also include information about social class, employment, and education, i.e. to jointly proxy for permanent income.
} 
relationship represents a behavior-specific transference from fathers to both sons and daughters. $^{21,22}$

\subsection{Extensive Margin Results for Juvenile and Adult Son Drunk Driving}

As individuals age into adulthood, it is possible that the mechanisms underlying their behaviors change. For instance, younger children may be more inclined to see their parents as role models and imitate their behaviors than older children. Thus, Table 5 replicates the extensive margin analysis presented in Table 4 for adult and juvenile drunk driving behavior separately.

Adult sons have more than twice the odds of being convicted of drunk driving if their father has a drunk driving record. However, adult sons no longer have significantly greater odds of being convicted of drunk driving when controlling for paternal alcoholism and the odds ratio decreases by nearly 60 percent. The odds ratio decreases further to 1.3 and remains insignificant when controlling for father criminality. The additional vectors of controls for inherited ability and physical characteristics as well social class and income do not further explain the fatheradult son drunk driving relationship. Thus, the relationship between the drunk driving behavior of adult sons and their fathers at the extensive margin appears to be primarily driven by general rather than behavior-specific mechanisms.

\footnotetext{
${ }^{21}$ The results presented in Table 4 are also robust to the use of the second definition of paternal drunk driving, i.e. Dad drunk driving 2. They are also robust to the inclusion of the cohort member's own drunken behavior. This behavior is a strong predictor for drunk driving, but explains none of the father-child relationship in drunken driving. ${ }^{22}$ In Table 4, we control for parental alcoholism and father's criminality first. These three variables decrease the father - son relationship by 60 percent. The remaining control variables for ability, physical characteristics and socio-economic status do not decrease this relationship any further. If we, instead, control for ability, physical characteristics and socio-economic status first, then these variables decrease the father - son relationship by 32 percent. Parental alcoholism and father's criminality now account for only 26 percent of the total decrease. This illustrates the main difficulty faced by this type of accounting exercise. The ordering of the variables matters since our variables are correlated with each other and since parental alcoholism and criminality may affect their children's drunk driving behavior through several channels, including behavioral mechanisms, social mechanisms and genetics. One can interpret the 26 percent decrease in the father - son relationship accounted for by parental alcoholism and criminality after controlling for socio-economic status, ability and physical characteristics as a lower bound on the total effect of parental alcoholism and criminality due to the combined effect of nature and nurture. Social mechanisms are most likely controlled away.
} 
The same cannot be said for juvenile drunk driving behavior. Sons with drunk driving fathers have 3.4 times the odds of having a drunk driving conviction as a juvenile than sons without drunk driving fathers. The odds ratio decreases to 2.3 (by 45 percent), but remains highly significant, when controlling for paternal alcoholism. In addition, this odds ratio is not sensitive to the inclusion of any additional controls: maternal alcoholism, paternal criminality, inherited ability and physical characteristics, and common background characteristics.

Why is the intergenerational drunk driving relationship for adult cohort members mostly accounted for with controls for paternal alcoholism while that for juvenile drunk driving behavior appears to be, at least in large part, driven by a behavioral specific transference mechanism? One potential explanation is that the underlying transference mechanism actually changes as a cohort member ages. For instance, this would be consistent with juveniles being more impressionable and likely to treat their fathers as role models. An alternative explanation is that these two sets of regressions capture different types of cohort members; that is, those cohort members convicted of drunk driving as a juvenile may be different than those convicted of drunk driving as an adult. For instance, those with an adult drunk driving record may be more likely to be repeat offenders. However, defining the dependent variables in Table 5 as only having a drunk driving record as a juvenile or adult indicates that this is not the case: the same juvenile versus adult pattern remains. We have also examined whether those convicted of drunk driving as a juvenile versus an adult (or both) systematically differ in observable characteristics, including ability, family background (social class, paternal employment, paternal income), parental alcoholism and criminality, and education. Few significant differences are observed between those with only juvenile $(n=156)$ and only adult $(n=396)$ drunk driving records. However, those with drunk driving records in both periods $(n=74)$ are significantly more likely to have 
alcoholic fathers and obtain significantly less education (as of the 1970 census) than cohort members with a drunk driving record in one period only.

\section{Conclusion}

This paper uses administrative drunk driving data on a 1953 Stockholm birth cohort and their parents to study the intergenerational nature of drunk driving. A strong intergenerational relationship is observed for both sons and daughters - children with drunk driving fathers have more than 2.5 times the odds of having a drunk driving conviction themselves than children without drunk driving fathers. In addition, this intergenerational pattern is already visible when examining the juvenile drunk driving behavior of the cohort members.

Why does this intergenerational drunk driving relationship exist? Our results point towards the importance of a behavioral transference mechanism. The character of this mechanism, however, appears to change over time, as cohort members age into adulthood. In particular, the relationship between the drunk driving behavior of adult sons and their fathers appears to be primarily driven by general alcohol abusing and law breaking behaviors while the relationship observed for juvenile sons appears to be, at least in large part, driven by a behaviorspecific transference mechanism. This is consistent with juveniles being more impressionable and likely to treat their fathers as role models and is further evidence of specificity in the intergenerational transmission of bad habits as posited by Duncan et al. (2005).

The fact that behavioral mechanisms are key in explaining why intergenerational correlations in drunk driving exist implies that policies that treat or deter alcohol abuse and criminal behavior may have larger effects than previously believed since they also entail a "second generation" effect. In particular, policies that deter drunk driving among parents will 
most likely lower the rate of drunk driving among young adults (their children). Our findings also suggest that it may be appropriate to consider a more family-oriented approach when designing treatment programs for drunk drivers.

Finally, though the traditional regression analysis presented in this paper points towards the importance of behavioral mechanisms (both specific and general) as an explanation for the intergenerational drunk driving correlation and the general irrelevance of inheritable traits such as ability and physical characteristics, it is clear that our controls are inadequate proxies for all types of inherited characteristics. In particular, we are not able to separate the important influence that parental alcoholism has on their children's drunk driving behavior into unique components - one due to the genetic inheritance of alcohol use and abuse and a second due to the behavioral inheritance of alcohol use and abuse. Thus, one would like to use alternative approaches to test the relative importance of these underlying mechanisms and to check the robustness of our behavioral story. For instance, with a sample of adopted individuals, one could regress cohort member drunk driving on whether the cohort member is adopted, whether the father has a drunk driving record, and an interaction between the two. A zero interaction effect would imply a social or behavioral model and that inherited traits do not matter much. Unfortunately, the SBC data only includes 252 adoptees, 16 of whom have any drunk driving convictions and only 4 of whom have a father with a drunk driving conviction.

Alternatively, one can use sibling correlations to measure of the importance of family and community effects, including anything shared by siblings (e.g., parental characteristics, such as fathers' drunk driving), as well as things not directly experienced in the home (e.g., school, church and neighborhood effects). The SBC data consists of 144 pairs of twins, but only 12 of these individuals have any drunk driving convictions. Twin drunk driving correlations in the 
SBC data indicate that approximately 33 percent of the drunk driving behavior can be attributed to family and community background effects. ${ }^{23}$ A weakness of this approach, however, is that one cannot distinguish between many of the various mechanisms: "family background" captures drunk driving fathers, alcoholic fathers, criminal fathers, etc. Ideally, one can compare sibling drunk driving correlations for monozygotic and dizygotic twins to obtain a direct measure of the potential importance of inherited traits for drunk driving behavior and, hence, a direct (genetic) link between fathers' drunk driving and that of their children. If genetics matter, then the correlation between monozygotic twins criminal behavior should be larger than that found for dizygotic twins. Though zygoticity is identified in the SBC data, sample size issues combined with the limited prevalence of drunk driving behavior once again limit our ability to conduct this analysis.

Thus, our future research agenda includes both adoptee and twin analyses using an alternative source of data. In particular, we will obtain a 25 percent sample of Statistics Sweden's multigenerational register and merge it with: (i) parent, sibling and children identifiers, (ii) income and education data, (iii) childhood neighborhood and family structure data, and (iv) Sweden's national crime register. The opportunity to use a national crime register, let alone merge it with the other administrative data, will result in a truly unique data set that is ideal to further study the role of both the family and neighborhood in determining criminal and drunk driving behavior.

\footnotetext{
${ }^{23}$ We have also run sibling correlations for drunk driving using both the 1997 and 1979 National Longitudinal Surveys of Youth (NLSY). A weakness of these surveys, however, is that a question about drinking and driving is only asked in one survey round (2002 for the NLSY97 and 1989 for the NLSY79) and it only pertains to behavior in the last 30 days. The correlations between all sibling pairs are significant at both the extensive and intensive margins for both the NLSY97 and NLSY79. The extensive margin correlation is equal to 0.11 in the NLSY97 and 0.19 in the NLSY79.
} 


\section{References}

Anderson, P. and B. Baumberg (2006), "Alcohol in Europe: A Public Health Perspective Report to the European Commission," London: Institute of Alcohol Studies. (http://ec.europa.eu/health-eu/news_alcoholineurope_en.htm).

Argeriou, M., D. McCarty and E. Blacker (1985), "Criminality Among Individuals Arraigned for Drinking and Driving in Massachusetts," Journal of Studies on Alcohol 46, 525-529.

Beerman, K. A., M. M. Smith, and L. R. Hall (1988), "Predictors of recidivism in DUIs," Journal of Studies on Alcohol 49, 443-449.

Björklund, Anders and Markus Jäntti (forthcoming), "Intergenerational Income Mobility and the Role of Family Background", in Wiemer Salverda, Brian Nolan and Tim Smeeding (Eds.) Oxford Handbook of Economic Inequality, Oxford University Press, 2009.

Blazei, Ryan W., William G. Iacono and Robert F. Krueger (2006), "Intergenerational Transmission of Antisocial Behavior: How Do Kids become Antisocial Adults?" Applied and Preventative Psychology 11, 230-253.

Blincoe L., A. Seay, E. Zaloshnja, T. Miller, E. Romano, S. Luchter (2002), "The Economic Impact of Motor Vehicle Crashes, 2000," U.S. Department of Transportation, National Highway Traffic Safety Administration, Washington D.C..

BRA (1995) (The Swedish National Council for Crime Prevention), "Rattfylleribrottets historia 70 år” (The History of Drunken Driving over 70 Years), Rapport 1995:2.

BRA (2007) (The Swedish National Council for Crime Prevention), "Brottsutvecklingen i Sverige fram till år 2007. Kapitel: Rattfylleri” (The Development of Crime in Sweden until 2007. Chapter: Drunken Driving), Rapport 2008:23.

Carpenter, Christopher, and Katharine Harris (2005), "How Do 'Point Oh-Eight' (.08) BAC Laws Work?" B.E. Journals in Economic Analysis and Policy: Topics in Economic Analysis and Policy 5(1), 1-18.

Carpenter, Christopher S., Deborah D. Kloska, Patrick O'Malley, and Lloyd Johnston (2007), "Alcohol Control Policies and Youth Alcohol Consumption: Evidence from 28 Years of Monitoring the Future," B.E. Journal of Economic Analysis and Policy: Topics in Economic Analysis and Policy 7(1), 1-21.

Carpenter, Christopher and Carlos Dobkin (2009), "The Effect of Alcohol Consumption on Mortality: Regression Discontinuity Evidence from the Minimum Drinking Age," American Economic Journal: Applied Economics 1(1), 164-182.

Cavaiola, Alan and Charles Wuth (2002), Assessment and Treatment of the DWI Offender, The Haworth Press, New York. 
Cook, Philip J. (2007), Paying the Tab: The Costs and Benefits of Alcohol Control, Princeton University Press, Princeton.

Corak, Miles (2006), "Do Poor Children Become Poor Adults? Lessons from a Cross Country Comparison of Generational Earnings Mobility," Research on Economic Inequality 13(1), 143188.

Cosper, Ronald and Kenneth Mozersky (1968), "Social Correlates of Drinking and Driving," Quarterly Journal of Studies on Alcohol, Supplement No. 4 (May).

Cox, Richard Guy (2006), "A Perverse Effect of Lowering the Threshold Blood Alcohol Content," Applied Economics Letters 13(13), 869-871.

De Ribeaux, Mary Beth (1997), "A Critical Analysis of COS Research," Alcohol Health \& Research World 21(3), 258-264.

Dee, T. S. (2001), "Does setting limits save lives? The case of 0.08 BAC laws," Journal of Policy Analysis and Management 20, 111-128.

Department of Justice (2006), "Crime in the United States 2005: Uniform Crime Reports," U.S. Department of Justice, Federal Bureau of Investigation, Washington D.C.

Duncan, Greg, Ariel Kalil, Susan Mayer, Robin Tepper, and Monique Payne (2005), "The Apple Does Not Fall Far From the Tree," in Samuel Bowles, Herbert Gintis and Melissa Osborne Groves (eds.), Unequal Chances: Family Background and Economic Success, Princeton University Press, Princeton.

Eisenberg, Daniel (2003), "Evaluating the Effectiveness of Policies Related to Drunk Driving," Journal of Policy Analysis and Management 22(2), 249-274.

Ellis, Deborah A., Robert A. Zucker and Hiram E. Fitzgerald (1997), "The Role of Family Influences in Development and Risk," Alcohol Health \& Research World 21(3), 218-226.

Ehrlich, N.J., and M.L. Selzer (1967), "A Screening Procedure to Detect Alcoholism." In Traffic Offenders in the Prevention of Highway Injury, edited by M.L. Selzer, P.W. Gikas, and F.F. Hueke. Ann Arbor, Mich.: University of Michigan, Highway Safety Research Institute

Erikson R. and J. H. Goldthorpe (1992), The Constant Flux - A Study of Class Mobility in Industrial Societies, The Clarendon Press, Oxford.

Farrington, David P., Jeremy W. Coid and Joseph Murray (2009), "Family Factors in the Intergenerational Transmission of Offending”, Criminal Behaviour and Mental Health 19(2), $109-124$.

Freeman, Donald G. (2007), "Drunk Driving Legislation and Traffic Fatalities: New Evidence on BAC 08 Laws," Contemporary Economic Policy 25(3), 293-308. 
Hauge, Ragnar (editor) (1978), "Drinking and Driving in Scandinavia," Scandinavian Studies in Criminology, vol. 6, Universitetsforlaget, Oslo.

Hjalmarsson, Randi and Matthew Lindquist (2007), "Like Godfather, Like Son: Explaining the Intergenerational Nature of Crime," working paper.

Hyman, Merton (1968), "The Social Characteristics of Persons Arrested for Driving While Intoxicated," Quarterly Journal of Studies on Alcohol, Supplement No. 4 (May).

Jacob, Theodore and Sheri Johnson (1997), "Parenting Influences on the Development of Alcohol Abuse and Dependence," Alcohol Health \& Research World 21(3), 204-209.

Jacobs, James B. (1989), Drunk Driving, University of Chicago Press, Chicago.

Levitt, Steven D. and Jack Porter (2001), "How Dangerous Are Drinking Drivers?" Journal of Political Economy 109(6), 1198-1237.

Mazumder, Bhashkar (2008), "Sibling Similarities and Economic Inequality in the US," Journal of Population Economics 21(3), 685-701.

McGue, Matt (1997), "A Behavioral-Genetic Perspective on Children of Alcoholics," Alcohol Health \& Research World 21(3), 210-217.

Moskowitz, H., J. Walker and C. Gomberg (1979), "Characteristics of DWIs, Alcoholics and Controls," in Proceedings of the 1979 NCA Alcohol and Traffic Safety Session, Washington, DC: National Highway Traffic Safety Administration, 9-79.

NHTSA (2007), “Traffic Safety Facts 2005: Alcohol,” U.S. Dept of Transportation, National Highway Traffic Safety Administration, Washington D.C.

Norström, Thor (1978), "Drunken Driving: A Tentative Causal Model," Scandinavian Studies in Criminology 6, 69-78.

Norström, Thor (1996), "Drunken Driving, Alcohol Misuse and Criminality," Studies on Crime and Crime Prevention 5, 105-112.

Quinlan, K. P., R. D. Brewer, P. Siegel, D. A. Sleet, A. H. Mokdad, R. A. Shults and N. Flowers (2005), "Alcohol-impaired driving among U.S. adults, 1993-2002," American Journal of Preventive Medicine 28(4), 345-350.

Ross, Laurence H. (1978), "Scandinavia's Drinking-and-Driving Laws: Do They Work?" Scandinavian Studies in Criminology 6, 55-60.

Ruhm, Christopher J. (1996), "Alcohol Policies and Highway Vehicle Fatalities," Journal of Health Economics 15(4), 435-454. 
Selzer, Melvin L. (1969), "Alcoholism, Mental Illness, and Stress in 96 Drivers Causing Fatal Accidents," Behavioral Science 14, 1-10.

Solon, Gary (1999), "Intergenerational Mobility in the Labor Market," in Orley C. Ashenfelter and David Card (eds.), Handbook of Labor Economics, vol. 3A, Amsterdam: North-Holland, 1761-1800.

Stenberg, Sten-Åke (2000), "Inheritance of Welfare Recipiency: An Intergenerational Study of Social Assistance Recipiency in Postwar Sweden," Journal of Marriage and the Family 62(1), 228-39.

Stenberg, Sten-Åke and Denny Vågerö (2006), "Cohort profile: The Stockholm Birth Cohort of 1953," International Journal of Epidemiology 35, 546-548.

Stenberg, Sten-Åke, Denny Vågerö, Reidar Österman, Emma Arvidsson, Cecelia Von Otter and Carl-Gunnar Janson (2007), "Stockholm Birth Cohort Study 1953-2003: A new tool for lifecourse studies," Scandinavian Journal of Public Health 35(1), 104-10.

van de Rakt, Marieke, Paul Nieuwbeerta and Robert Apel (2009), "Association of Criminal Convictions between Family Members: Effects of Siblings, Fathers and Mothers," Criminal Behaviour and Mental Health 19(2), 94-108.

VTI (2007) (The Swedish Government Road and Transport Research Institute), "Rattfylleriets omfattning: En metodstudie i Södermanlands, Örebro och Östergötlands län" (The Scope of Drunk Driving: A Methodologial Study in Södermanlands, Örebro and Östergötlands Counties), VTI Rapport 599.

Vägverket (2003) (The Swedish Road Administration), "Djupstudierapport over dödsolyckor i södra Sverige 1997-2002 (An In-Depth Report Concerning Fatal Accidents in Southern Sweden 1997-2002), Publikation 2003:136.

Vägverket (2008) (The Swedish Road Administration), “Alkohol, droger och trafik" (Alcohol, Drugs and Traffic), Broschyr 2008:06.

Waller, Julian (1967), "Identification of Problem Drinking among Drunken Drivers," Journal of American Medical Association 200: 114 - 120.

Windle, Michael (1997), "Concepts and Issues in COA Research," Alcohol Health \& Research World 21(3), 185-191.

Yoder, Richard and Robert Moore (1973), "Characteristics of Convicted Drunken Drivers," Quarterly Journal of Studies on Alcohol 34, 927-936. 
Table 1. Descriptive Statistics.

\begin{tabular}{|c|c|c|c|}
\hline Variable name & Definition & $\begin{array}{c}\text { Male } \\
(\mathrm{n}=7719) \\
\text { Mean } \\
\text { (s.d.) }\end{array}$ & $\begin{array}{l}\text { Female } \\
(\mathrm{n}=7398) \\
\text { Mean } \\
\text { (s.d.) }\end{array}$ \\
\hline \multicolumn{4}{|c|}{ Cohort Member Alcohol Related Variables ${ }^{(a)}$} \\
\hline $\begin{array}{l}\text { Any drunk } \\
\text { driving }\end{array}$ & $\begin{array}{l}1 \text { if any drunk driving or dui convictions } \\
\text { (drunkdrive_dui_combined) }\end{array}$ & $\begin{array}{c}0.081 \\
(0.273)\end{array}$ & $\begin{array}{c}0.005 \\
(0.069)\end{array}$ \\
\hline $\begin{array}{l}\text { Any adult drunk } \\
\text { driving }\end{array}$ & $\begin{array}{l}1 \text { if any drunk driving or dui convictions when age } 20 \text { or } \\
\text { older drive_dui_combined }\end{array}$ & $\begin{array}{c}0.061 \\
(0.239)\end{array}$ & $\begin{array}{c}0.004 \\
(0.062)\end{array}$ \\
\hline $\begin{array}{l}\text { Any juvenile } \\
\text { drunk driving }\end{array}$ & $\begin{array}{l}1 \text { if any drunk driving or dui convictions when age is less } \\
\text { than } 20 \text { drunkdr_wpbr }\end{array}$ & $\begin{array}{c}0.030 \\
(0.170)\end{array}$ & $\begin{array}{c}0.001 \\
(0.028)\end{array}$ \\
\hline $\begin{array}{l}\text { Number drunk } \\
\text { driving }\end{array}$ & $\begin{array}{l}\text { Number of drunk-driving and dui convictions in the official } \\
\text { police register at any age numdrive_dui_pbr }\end{array}$ & $\begin{array}{c}0.126 \\
(0.594)\end{array}$ & $\begin{array}{c}0.007 \\
(0.153)\end{array}$ \\
\hline $\begin{array}{l}\text { Any } \\
\text { drunkenness }\end{array}$ & 1 if any drunkenness convictions (drunkenness_all) & $\begin{array}{c}0.074 \\
(0.261)\end{array}$ & $\begin{array}{c}0.019 \\
(0.135)\end{array}$ \\
\hline $\begin{array}{l}\text { Any adult } \\
\text { drunkenness }\end{array}$ & 1 if any drunkenness convictions when age 20 or older & $\begin{array}{c}0.014 \\
(0.116)\end{array}$ & $\begin{array}{c}0.001 \\
(0.035)\end{array}$ \\
\hline $\begin{array}{l}\text { Any juvenile } \\
\text { drunkenness }\end{array}$ & 1 if any drunkenness convictions when age is less than 20 & $\begin{array}{c}0.067 \\
(0.249)\end{array}$ & $\begin{array}{c}0.018 \\
(0.133)\end{array}$ \\
\hline $\begin{array}{l}\text { Number } \\
\text { drunkenness }\end{array}$ & $\begin{array}{l}\text { Number of drunkenness convictions in the official police } \\
\text { register at any age numdrunkenness_all }\end{array}$ & $\begin{array}{c}0.025 \\
(0.236)\end{array}$ & $\begin{array}{c}0.002 \\
(0.055)\end{array}$ \\
\hline \multicolumn{4}{|c|}{ Parent Alcohol Related Variables ${ }^{(c)}$} \\
\hline $\begin{array}{l}\text { Mom drunk } \\
\text { driving }\end{array}$ & 1 if mother sentenced for drunk driving 1953-72 & $\begin{array}{c}0.000 \\
(0.011)\end{array}$ & $\begin{array}{c}0.000 \\
(0.012)\end{array}$ \\
\hline $\begin{array}{l}\text { Dad drunk } \\
\text { driving }\end{array}$ & 1 if father sentenced for drunk driving 1953-72 & $\begin{array}{c}0.016 \\
(0.124)\end{array}$ & $\begin{array}{c}0.018 \\
(0.131)\end{array}$ \\
\hline $\begin{array}{l}\text { Dad drunk } \\
\text { driving } 2\end{array}$ & $\begin{array}{l}1 \text { if father sentenced for drunk } \\
\text { driving } 1953-72 \text { in social register or drunk or dangerous } \\
\text { driving in the official police registrar }\end{array}$ & $\begin{array}{c}0.038 \\
(0.192)\end{array}$ & $\begin{array}{c}0.047 \\
(0.211)\end{array}$ \\
\hline Parent drunk & 1 if mother or father fined for drunkenness from $53-72$ & $\begin{array}{c}0.018 \\
(0.133)\end{array}$ & $\begin{array}{c}0.017 \\
(0.128)\end{array}$ \\
\hline Dad alcoholic & 1 if father is an alcoholic from $53-72$ & $\begin{array}{c}0.043 \\
(0.204)\end{array}$ & $\begin{array}{c}0.039 \\
(0.194)\end{array}$ \\
\hline Mom alcoholic & 1 if mother is an alcoholic from $53-72$ & $\begin{array}{c}0.008 \\
(0.087)\end{array}$ & $\begin{array}{c}0.005 \\
(0.073)\end{array}$ \\
\hline $\begin{array}{l}\text { Dad Criminal } \\
\text { Record }\end{array}$ & $\begin{array}{l}1 \text { if father has a criminal record in the official police } \\
\text { registrar other than drunk and dangerous driving } \\
\text { Father_noddd }\end{array}$ & $\begin{array}{c}0.097 \\
(0.297)\end{array}$ & $\begin{array}{c}0.103 \\
(0.305)\end{array}$ \\
\hline
\end{tabular}

(a) All extensive margin cohort member drunk driving and drunkenness measures are based on data reported in both the social register and official police registers. Intensive margin measures are only available from the official police registers.

(b) The average number of drunk driving and drunkenness offenses is substantially greater when considering the sub-samples of males and females who have any record of the behavior in the official police register. The average number of drunk driving offenses is approximately 1.6 for both males $(n=613)$ and females $(n=33)$. The average number of drunkenness offenses is 1.4 for males $(n=138)$ and 1.1 for females $(n=16)$.

(c) Parental alcohol related variables are sourced solely from the social registers, unless otherwise noted, i.e. Dad drunk driving 2. 
Table 2. Father-Child Drunk Driving Associations.

\begin{tabular}{lccc}
\hline Dependent Variables & All & Sons & Daughters \\
\hline $\begin{array}{l}\text { Cohort Member Variables } \\
\text { Any drunk driving }\end{array}$ & $2.590^{* * *}$ & $2.573 * * *$ & $7.411^{* * *}$ \\
Any juvenile drunk driving & $3.282^{* * *}$ & $3.369 * * *$ & $11.260^{* *}$ \\
Any adult drunk driving & $2.310^{* * *}$ & $2.222^{* * *}$ & $6.580^{* * *}$ \\
& & & \\
Number drunk driving & 1.017 & 0.854 & $2.122^{*}$ \\
\hline Observations & & & \\
\hline
\end{tabular}

Extensive margin results are odds ratios from univarite logistic regressions of the above indicated cohort member variable on Dad drunk driving. Intensive margin results are incidencerate ratios from univariate negative binomial regressions of Number drunk driving (>0) on Dad drunk driving; unfortunately, an intensive margin variable is not available for the father. Standard errors are robust; *** denotes significance at $1 \%$, ** denotes significance at $5 \%$, * denotes significance at $10 \%$. 
Table 3. Associations between Fathers' Drunk Driving and Children's Drunken Behavior.

\begin{tabular}{lccc}
\hline Dependent Variables & All & Sons & Daughters \\
\hline & & & \\
Any drunkenness & $1.592 *$ & 1.262 & $3.125^{* * * *}$ \\
Any juvenile drunkenness & $1.639 *$ & 1.411 & $2.699 * *$ \\
Any adult drunkenness & 2.153 & 1.850 & $7.035^{*}$ \\
& & & \\
\hline $\begin{array}{l}\text { Observations } \\
\text { Extensive margin results are odds ratios from univarite logistic regressions of the above indicated cohort } \\
\text { member variable on Dad drunk driving. Standard errors are robust; *** denotes significance at } 1 \%, * * \\
\text { denotes significance at 5\%, * denotes significance at } 10 \% .\end{array}$ &
\end{tabular}


Table 4. Explaining the Father-Child Relationship at the Extensive Margin

\begin{tabular}{|c|c|c|c|c|c|c|c|c|c|c|c|c|}
\hline & \multicolumn{6}{|c|}{ Sons } & \multicolumn{6}{|c|}{ Daughters } \\
\hline & $(1)$ & $(2)$ & (3) & (4) & $(5)$ & (6) & $(7)$ & $(8)$ & $(9)$ & $(10)$ & $(11)$ & $(12)$ \\
\hline Dad drunk driving & $2.573 * * *$ & $1.787 * *$ & $1.814 * *$ & $1.614 *$ & $1.662 *$ & $1.655^{*}$ & $7.411 * * *$ & $5.739 * * *$ & $5.678 * * *$ & $5.105^{* *}$ & $4.214 * *$ & $5.150 * *$ \\
\hline & {$[0.616]$} & {$[0.476]$} & {$[0.484]$} & {$[0.436]$} & {$[0.432]$} & {$[0.427]$} & [3.994] & {$[3.525]$} & {$[3.551]$} & [3.269] & {$[2.500]$} & [3.355] \\
\hline Dad alcoholic & & $3.101 * * *$ & $2.680 * * *$ & $2.330 * * *$ & $1.800 * * *$ & $1.721 * * *$ & & 1.907 & 1.678 & 1.483 & 1.213 & 1.245 \\
\hline & & {$[0.460]$} & {$[0.425]$} & {$[0.376]$} & {$[0.294]$} & {$[0.285]$} & & [1.168] & [0.997] & {$[0.855]$} & [0.649] & {$[0.756]$} \\
\hline Mom alcoholic & & & $3.459 * * *$ & $3.472 * * *$ & $2.826 * * *$ & $2.967 * * *$ & & & 2.695 & 2.618 & 1.907 & 2.191 \\
\hline & & & [1.096] & {$[1.128]$} & {$[0.941]$} & {$[1.000]$} & & & [2.998] & [2.876] & [2.061] & [2.456] \\
\hline Dad Criminal Record & & & & $1.662 * * *$ & $1.351 * *$ & $1.334 * *$ & & & & 1.550 & 1.256 & 1.562 \\
\hline & & & & {$[0.203]$} & {$[0.169]$} & {$[0.167]$} & & & & [0.689] & {$[0.539]$} & [0.703] \\
\hline Verbal Score ( $6^{\text {th }}$ grade $)$ & & & & & 1.004 & 1.007 & & & & & 0.966 & 0.955 \\
\hline & & & & & [0.009] & [0.009] & & & & & {$[0.029]$} & [0.030] \\
\hline Spatial score ( $6^{\text {th }}$ grade $)$ & & & & & 0.991 & 0.991 & & & & & $1.071 * *$ & $1.066^{*}$ \\
\hline & & & & & {$[0.007]$} & {$[0.007]$} & & & & & {$[0.035]$} & [0.036] \\
\hline Math score $\left(6^{\text {th }}\right.$ grade $)$ & & & & & 1.004 & 1.004 & & & & & 0.999 & 0.993 \\
\hline & & & & & {$[0.008]$} & {$[0.008]$} & & & & & {$[0.032]$} & {$[0.031]$} \\
\hline Spatial Score Missing & & & & & 1.170 & 1.192 & & & & & 0.506 & 0.472 \\
\hline & & & & & [0.859] & {$[0.850]$} & & & & & {$[0.264]$} & [0.295] \\
\hline Math Score Missing & & & & & 1.138 & 1.117 & & & & & 1.694 & 1.947 \\
\hline & & & & & {$[0.839]$} & {$[0.801]$} & & & & & {$[0.781]$} & {$[1.218]$} \\
\hline Grade 6 Marks & & & & & $0.993 * * *$ & $0.993 * * *$ & & & & & $0.989 * * *$ & $0.986 * * *$ \\
\hline & & & & & {$[0.001]$} & {$[0.001]$} & & & & & {$[0.004]$} & {$[0.004]$} \\
\hline Grade 6 Marks missing & & & & & 1.143 & 1.135 & & & & & 0.716 & 0.455 \\
\hline & & & & & {$[0.233]$} & {$[0.235]$} & & & & & {$[0.779]$} & {$[0.505]$} \\
\hline No draft data & & & & & 1.077 & 1.068 & & & & & & \\
\hline & & & & & {$[0.226]$} & {$[0.231]$} & & & & & & \\
\hline Instructions Score & & & & & $0.899 * *$ & $0.906^{* *}$ & & & & & & \\
\hline & & & & & {$[0.038]$} & {$[0.039]$} & & & & & & \\
\hline Verbal Score (draft) & & & & & $0.923 * *$ & $0.925 * *$ & & & & & & \\
\hline & & & & & {$[0.036]$} & {$[0.036]$} & & & & & & \\
\hline Spatial Score (draft) & & & & & $1.071 * *$ & $1.068 * *$ & & & & & & \\
\hline & & & & & {$[0.034]$} & {$[0.034]$} & & & & & & \\
\hline Technical Score (draft) & & & & & 1.005 & 1.006 & & & & & & \\
\hline & & & & & {$[0.031]$} & {$[0.031]$} & & & & & & \\
\hline Height & & & & & $0.997 *$ & $0.997 *$ & & & & & & \\
\hline & & & & & {$[0.002]$} & {$[0.002]$} & & & & & & \\
\hline Weight & & & & & 1.001 & 1.001 & & & & & & \\
\hline & & & & & [0.005] & {$[0.005]$} & & & & & & \\
\hline Deviation from normal & & & & & 1.003 & 1.003 & & & & & & \\
\hline weight & & & & & {$[0.002]$} & {$[0.002]$} & & & & & & \\
\hline lowerwhitecollar53 & & & & & & 1.389 & & & & & & $0.166^{* *}$ \\
\hline
\end{tabular}




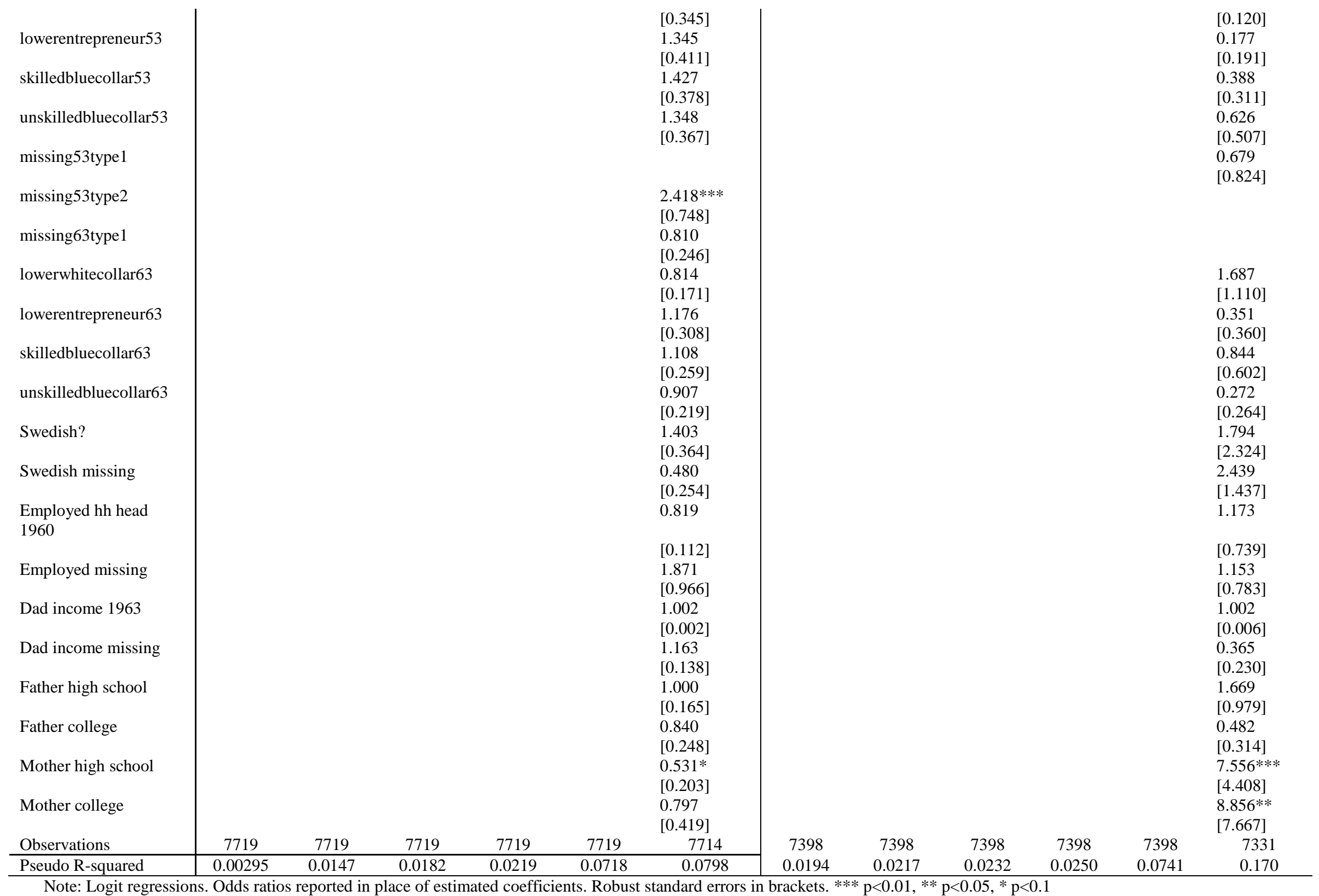


Table 5. Explaining the Father-Son Relationship at the Extensive Margin as a Juvenile and an Adult

\begin{tabular}{|c|c|c|c|c|c|c|c|c|c|c|c|c|}
\hline & \multicolumn{6}{|c|}{ Sons drunk driving as an adult (age $>=20$ ) } & \multicolumn{6}{|c|}{ Sons drunk driving as a juvenile (age $<20$ ) } \\
\hline & (1) & $(2)$ & (3) & (4) & (5) & (6) & (7) & $(8)$ & (9) & $(10)$ & $(11)$ & (12) \\
\hline Dad drunk driving & $2.222 * * *$ & 1.491 & 1.509 & 1.317 & 1.362 & 1.352 & $3.369 * * *$ & $2.303 * *$ & $2.367 * *$ & $2.251 * *$ & $2.336 * *$ & $2.301 * *$ \\
\hline & {$[0.622]$} & {$[0.461]$} & {$[0.468]$} & {$[0.410]$} & {$[0.414]$} & {$[0.410]$} & {$[1.090]$} & {$[0.838]$} & {$[0.855]$} & {$[0.833]$} & {$[0.835]$} & {$[0.811]$} \\
\hline Dad alcoholic & & $3.234 * * *$ & $2.920 * * *$ & $2.476 * * *$ & $1.929 * * *$ & $1.898 * * *$ & & $3.034 * * *$ & $2.485 * * *$ & $2.350 * * *$ & $1.749 * *$ & $1.632 * *$ \\
\hline & & {$[0.527]$} & {$[0.511]$} & {$[0.442]$} & {$[0.346]$} & {$[0.347]$} & & {$[0.687]$} & {$[0.612]$} & {$[0.590]$} & {$[0.420]$} & [0.399] \\
\hline Mom alcoholic & & & $2.410 * *$ & $2.416 * *$ & $2.024 *$ & $2.116^{* *}$ & & & $3.975^{* * *}$ & $3.961 * * *$ & $3.210 * * *$ & $3.394 * * *$ \\
\hline & & & {$[0.876]$} & {$[0.890]$} & {$[0.756]$} & {$[0.797]$} & & & {$[1.593]$} & {$[1.596]$} & [1.292] & {$[1.365]$} \\
\hline Dad Criminal Record & & & & $1.788 * * *$ & $1.479 * * *$ & $1.454 * * *$ & & & & 1.237 & 0.992 & 1.000 \\
\hline & & & & {$[0.240]$} & {$[0.203]$} & {$[0.200]$} & & & & {$[0.260]$} & {$[0.202]$} & [0.204] \\
\hline Observations & 7719 & 7719 & 7719 & 7719 & 7719 & 7714 & 7719 & 7719 & 7719 & 7719 & 7719 & 7714 \\
\hline Pseudo R-squared & 0.00190 & 0.0144 & 0.0160 & 0.0209 & 0.0642 & 0.0723 & 0.00506 & 0.0153 & 0.0203 & 0.0208 & 0.0750 & 0.0842 \\
\hline $\begin{array}{l}\text { Ability and Physical } \\
\text { Characteristic Controls }\end{array}$ & NO & NO & NO & NO & YES & YES & NO & NO & NO & NO & YES & YES \\
\hline $\begin{array}{l}\text { Social Class and } \\
\text { Income Controls }\end{array}$ & NO & NO & NO & NO & NO & YES & NO & NO & NO & NO & NO & YES \\
\hline
\end{tabular}

Note: Logit regressions. Odds ratios reported in place of estimated coefficients. Robust standard errors in brackets. $* * * \mathrm{p}<0.01, * * \mathrm{p}<0.05, * \mathrm{p}<0.1$ 